\title{
Comparative Analysis of Two Methodologies for Determination of HDL Cholesterol
}

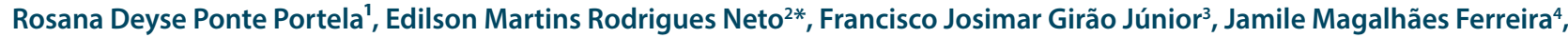 \\ Renata de Sousa Alves ${ }^{1}$, Teresa Maria de Jesus Ponte Carvalho', Benvindo Aécio Pinheiro Holanda' \\ 'Department of Clinical Analysis, Federal University of Ceará. Fortaleza- Ceará, BRAZIL. \\ 2Department of Pharmacy, Federal University of Ceará/ Catholic University Center of Quixadá. Fortaleza- Ceará, BRAZIL. \\ 32Department of Physiology and Pharmacology, Federal University of Ceará. Fortaleza- Ceará, BRAZIL. \\ ${ }^{4}$ University of International Integration of Afro-Brazilian Lusophony, Redenção-Ceará, BRAZIL.
}

\begin{abstract}
Objective: The present work is an analytical and prospective study on the determination of HDL-cholesterol through two different methodologies, precipitation and direct method, in a group of 51 patients attended by a school laboratory. Method: For the determination of these analytes, two methodologies were used: direct method and precipitation method, because it has been observed experimentally discrepancies in the values referring to the results of determination of cholesterol-HDL when comparing the results from the two methodologies, which can lead to a failed therapy. Result: Of the 51 samples analyzed, 38 (74.5\%) were female and 13 $(25.5 \%)$ were male. The results were divided into groups by age group, in order to verify a possible difference between the groups, the age range was 11 to 88 years. When the HDL-cholesterol values obtained by the two different methods were evaluated, there was a significant difference ( $p<0.0001)$ in the HDL-cholesterol values between the direct method $(56.06 \pm 1.653)$ and the precipitation method (39.35 \pm 1.193$)$. Conclusion:
\end{abstract}

For HDL values, it was possible to verify that there is a significant increase between the HDL-cholesterol values obtained by the direct method in relation to the method by precipitation independent of variables such as sex and age group. This way further studies are needed in order to find a pattern of variation between the methods and allow the adequacy of the results through a correction factor or even new reference values.

Key words: Cholesterol HDL, Benchmarking, Lipid Metabolism, Dyslipidemias.

\section{Correspondence}

Dr. Edilson Martins Rodrigues Neto, Quixadá Catholic university center, Juvêncio Alves Street, 660, Center. Quixadá, CE, BRAZIL.

Phone: +55 85999385790

Email: edilsonmrneto@hotmail.com

DOI: 10.5530/jyp.2018.10.68

\section{INTRODUCTION}

It is known, in the current context, that cholesterol levels, especially LDL and HDL fractions are predictors of elevated risk of atherosclerotic disease, when they are altered. ${ }^{1-2}$

Studies of possible discrepancies between the two methods for HDLcholesterol dosing are still scarce, making it impossible to make clear statements about the subject.

In one study it was possible to observe an increase in the HDL-cholesterol values by the direct method when compared to the ones found by the precipitation method, being a significant difference. The same result was observed when the patients were separated by groups: patients with normal values of total cholesterol and patients with altered total cholesterol values. ${ }^{3}$

These results corroborate a similar study, which also reported that the variation between the two methodologies implied in statistically significant differences in the LDL cholesterol values obtained by Friedewald's formula. ${ }^{4}$

According to the Brazilian Society of Cardiology, from the clinical and physiological point of view, the most biologically important lipids are phospholipids, cholesterol, triglycerides and fatty acids. Since phospholipids form the basic structure of cell membranes; cholesterol is a precursor of bile acids, steroid hormones and vitamin $\mathrm{D}$, besides being a component of cell membranes that acts on the fluidity of these and the activation of enzymes found there; and triglycerides, composed of fatty acids, are one of the most important forms of energy storage in the body. ${ }^{5}$
The consumption of trans and unsaturated fats is proportional to the increase in plasma cholesterol levels, and cholesterol consumption itself has less relevance in lipid profile variations. ${ }^{6}$ These habits are stimulated by the practicality and low cost of consumption of empty calories from industrialized foods; being these highly palatable and attractive to consumption, however presenting high levels of carbohydrates and saturated and trans fats. ${ }^{7}$ The literature reports that the etiology of these metabolic disorders can also be correlated with genetic characteristics and life habits that lead to physical and psychological exhaustion such as alcohol consumption and smoking, as well as sedentary lifestyle. ${ }^{8}$

The cholesterol and triglycerides ingested daily are transported between the organs and tissues with the help of lipoproteins, these are composed of lipids and proteins called apoproteins. ${ }^{5}$ There are five main classes of lipoproteins: chylomicrons, very low density lipoprotein (VLDL), intermediate density lipoprotein (IDL), low density lipoprotein (LDL) and high density lipoprotein (HDL), differing from one another, according to apoprotein composition, density, size and electrophoretic mobility. ${ }^{3}$

HDL cholesterol has the function of "cleaning" the arteries, transporting the cholesterol to the liver, where it will be metabolized and its excretion carried by the bile, thus presenting a beneficial function in the body. ${ }^{9}$

Each lipoprotein has a specific function within the organism. In the routine of most laboratories, determinations of triglycerides, total cholesterol and HDL-cholesterol are performed by the colorimetric enzymatic method, 
Portela, et al.: Analysis of Two Methodologies for Determination of HDL Cholesterol

using specific reagents. It is noteworthy that for HDL-cholesterol two possible methodologies are available (direct and precipitation method).$^{10}$ Published data revealed that $40 \%$ of the Brazilian population had elevated cholesterol levels and $12 \%$ had these values classified as high, in this context the quantification of total cholesterol and fractions is presented as an important tool to prevent cardiovascular risk. ${ }^{11}$

The precipitation method is based on the principle of the separation of lipoproteins from low (LDL-c) and very low (VLDL-c) densities based on the selectivity of phosphotungstate and magnesium ions. The samples are treated with phosphotungstic acid and magnesium chloride, which promotes the precipitation of all lipoproteins except the HDL fraction. After this pretreatment, the samples are centrifuged in order to separate the HDL fraction (supernatant) from the non-HDL fraction (precipitate). After separation, the HDL-cholesterol contained in the supernatant is determined in a spectrophotometer by enzymatic-colorimetric method, similar to the determination of total cholesterol. ${ }^{12}$

The direct method, however, allows a direct determination without the need for previous precipitation or treatment of the sample, since it uses reagents that perform the selective dosage of HDL-bound cholesterol. This method consists of a two-step reaction: in the first step human anti$\beta$-lipoprotein antibodies bind to low molecular weight proteins (LDL-c, VLDL-c and chylomicrons) leaving HDL-cholesterol free. In the second step the enzymes cholesterol esterase and cholesterol oxidase act on the cholesterol linked to the high density lipoprotein (HDL) and, in a sequence of reactions, they form hydrogen peroxide $\left(\mathrm{H}_{2} \mathrm{O}_{2}\right)$. This, in the presence of the peroxidase and a chromogenic substance, forms a colored compound, which can be quantified by the conventional analyzers. Thus the intensity of the staining formed is proportional to the concentration of HDL cholesterol in the sample. ${ }^{3,13}$

Studies report that an increase of $1.0 \mathrm{mg} / \mathrm{dL}$ in serum levels of HDL-c results in reduced risk of coronary heart disease by 2 to $3 \%$ (1). Others report that a decrease of $4.0 \mathrm{mg} / \mathrm{dL}$ is related to a $10 \%$ increase in the risk of cardiovascular diseases. ${ }^{14}$

It is then observed that it is of great importance that the results of HDL cholesterol determinations are accurate and reliable, especially for patients with borderline values, where the variation resulting from the methodology used may interfere with the interpretation of the clinical picture. Thus, it is important to know the available methodologies, so that there are no misinterpretations regarding the diagnosis and dyslipidemias monitoring. ${ }^{3-4}$

Because of this, the laboratories have a new function: to indicate the methodology used for HDL-c dosage; so that the clinician having the knowledge of available methodologies can monitor and / or correctly diagnose changes in serum lipids, avoiding changes of conduct in function of the different results obtained with the different methodologies available in the market..$^{3-4}$ Considering the above, it is proposed to compare the results of two methodologies (direct and by precipitation) for the determination of HDL-cholesterol, verifying if there are discrepancies in the results of the two methodologies analyzed and estimating a factor that can be used to relate the results under the two methodologies.

\section{METHODOLOGY}

The present study is an analytical and prospective study on the determination of HDL-cholesterol through two different methodologies, performed at the Laboratory of Clinical and Toxicological Analysis (LCTA) of the Federal University of Ceará (UFC), in a group of 51 patients who sought LACT for laboratory tests, including lipid profile (total cholesterol, fractions of LDL, HDL, triglycerides) and who accepted to participate in the study, by signing the Informed Consent Term (ICT). All patients were enrolled in the study, ranging from 11 to 88 years old and excluded from repeated cases, i.e, no more than one patient was collected. Serum samples from the patients were analyzed using two HDL-cholesterol methodologies: precipitation method and direct method.

The method for determination of cholesterol HDL fraction by precipitation is based on the treatment of samples with phosphotungstic acid and magnesium chloride, which promotes the precipitation of chylomicrons, VLDL and LDL, allowing, after centrifugation, the HDL fraction remaining in the supernatant can be determined by colorimetric enzymatic reaction. The determinations were made using the recommended technique and following the recommendations of the manufacturer (Bioclin ${ }^{\circledast}$ ) in semi-automation apparatus.

The direct method for determining the HDL cholesterol fraction allows a direct determination without the need for previous precipitation or treatment of the sample. It uses reagents that perform selective dosing of HDL-bound cholesterol. The low density lipoprotein (LDL), very low density (VLDL) and chylomicrons surfaces are stabilized by the adsorption of a polyanion and do not undergo the action of the modified enzymes present in the reagent. HDL, however, is solubilized by the action of a detergent, allowing the enzymatic action on the cholesterol attached to it. In this way, the intensity of the staining is proportional to the HDL cholesterol concentration in the sample. The determinations were made using the recommended technique and following the manufacturer's recommendations (Bioclin ${ }^{\star}$ ) in an automation device.

The results obtained from the determination of HDL were compiled into a table for subsequent analysis of the variables, that is, of the values obtained for HDL-cholesterol through the two methodologies, using GraphPad Prism version 6.0 software for Windows and the project was submitted to Research Ethics Committee of the Federal University of Ceará by Resolution 466 of the National Health Council - NHC of the Ministry of Health, considering the respect for human dignity and the special protection due to the participants of scientific researches involving human beings, being approved under the opinion number 1,026,288.

\section{RESULTS}

Of the 51 samples analyzed, 38 (74.5\%) were female and 13 (25.5\%) were male. The age range was 11 to 88 years.

In order to compare the HDL-cholesterol values obtained by the two methodologies evaluated, the data were initially assessed with mean and standard deviation (Table 1).

When the HDL-cholesterol values obtained by the two different methods were evaluated, there was a significant difference $(p<0.0001)$ in the

Table 1: Mean values of HDL-cholesterol in $\mathrm{mg} / \mathrm{dL}$ obtained by the two methodologies (direct and precipitated).

\begin{tabular}{|c|c|c|c|c|c|}
\hline Variable & $\begin{array}{l}\text { HDL-c (mg/dL) Direct } \\
\text { method }\end{array}$ & $\begin{array}{c}\text { HDL-c }(\mathrm{mg} / \mathrm{dL}) \\
\text { Method by precipitation }\end{array}$ & $\begin{array}{c}\text { Direct-precipitated HDL-c } \\
\text { variation }(\mathrm{mg} / \mathrm{dL})\end{array}$ & $\%$ change & $\begin{array}{l}\text { Test t between HDL-c } \\
\text { direct-precipitate }\end{array}$ \\
\hline General & $56,06 \pm 11,81$ & $39,35 \pm 8,52$ & $16,71 \pm 6,07$ & $29,54 \pm 7,66$ & $\mathrm{p}<0,0001$ \\
\hline Female & $57,66 \pm 11,46$ & $40,29 \pm 8,00$ & $17,37 \pm 6,57$ & $29,71 \pm 8,20$ & $\mathrm{p}<0,0001$ \\
\hline Male & $51,38 \pm 12,00$ & $36,62 \pm 9,691$ & $14,77 \pm 3,85$ & $29,05 \pm 6,08$ & $\mathrm{p}<0,0001$ \\
\hline
\end{tabular}




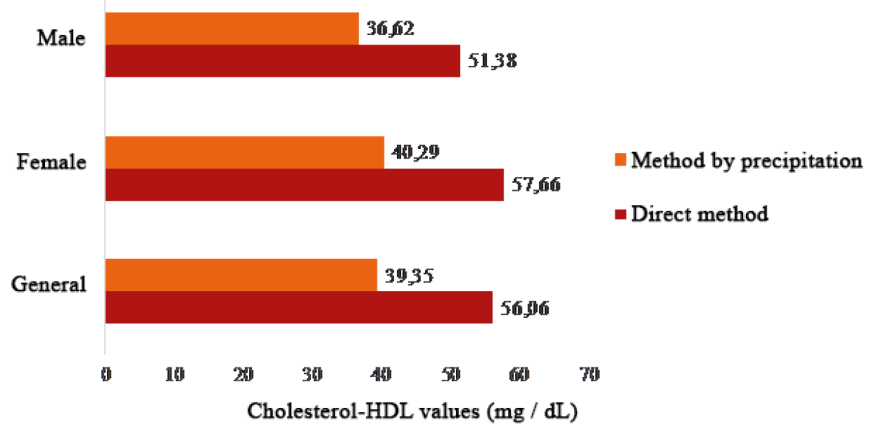

Figure 1: Comparison between HDL-cholesterol values obtained by direct and precipitation methods.

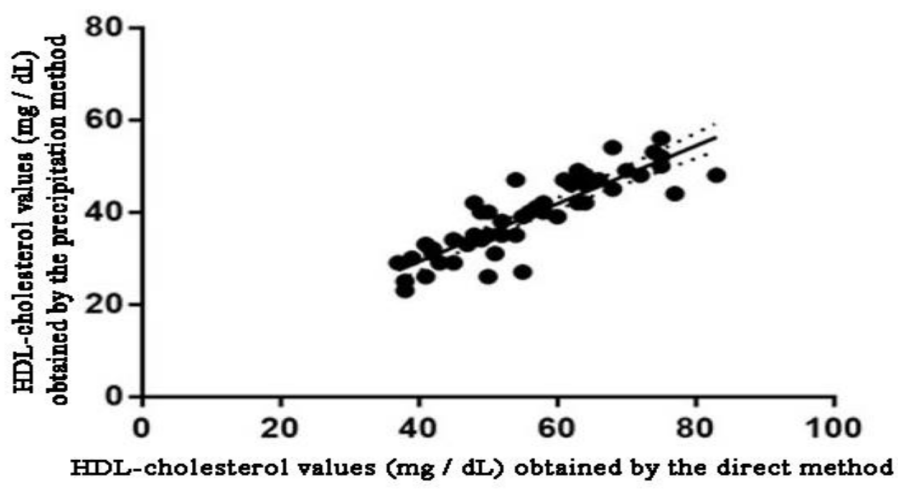

Figure 2: Graphical representation of the comparison of the HDL-cholesterol dosage by the direct method and by the precipitation method.

Table 2: Mean and standard deviation for HDL-cholesterol values $\geq 40 \mathrm{mg} / \mathrm{dL}$.

\begin{tabular}{ccccc}
\hline Variable & $\begin{array}{c}\text { HDL-c }(\mathrm{mg} / \mathrm{dL}) \\
\text { Direct method }\end{array}$ & $\begin{array}{c}\text { HDL-c }(\mathrm{mg} / \mathrm{dL}) \\
\text { Method by precipitation }\end{array}$ & $\begin{array}{c}\text { Direct-precipitated HDL-c } \\
\text { variation }(\mathrm{mg} / \mathrm{dL})\end{array}$ & $\begin{array}{c}\text { \% change } \\
\text { Test t between HDL-c direct-precipitate }\end{array}$ \\
\hline General & $64,37 \pm 8,99$ & $46,15 \pm 4,55$ & $18,22 \pm 6,72$ & $27,59 \pm 7,25$ \\
Female & $64,41 \pm 9,78$ & $46,05 \pm 4,55$ & $18,36 \pm 7,34$ & $27,62 \pm 7,79$ \\
Male & $64,20 \pm 4,82$ & $46,60 \pm 5,08$ & $17,60 \pm 3,21$ & $27,46 \pm 4,75$ \\
\hline
\end{tabular}

Table 3: Mean and standard deviation for HDL-cholesterol values $<40 \mathrm{mg} / \mathrm{dL}$.

\begin{tabular}{cccccc}
\hline Variable & $\begin{array}{c}\text { HDL-c }(\mathrm{mg} / \mathrm{dL}) \\
\text { Direct method }\end{array}$ & $\begin{array}{c}\text { HDL-c }(\mathrm{mg} / \mathrm{dL}) \\
\text { Method by precipitation }\end{array}$ & $\begin{array}{c}\text { Direct-precipitated } \\
\text { HDL-c variation }(\mathbf{m g} / \mathrm{dL})\end{array}$ & $\begin{array}{c}\text { \% change } \\
\text { dest t between HDL-c } \\
\text { direct-precipitate }\end{array}$ \\
\hline General & $46,71 \pm 6,27$ & $31,71 \pm 4,37$ & $15,00 \pm 4,83$ & $31,73 \pm 7,67$ & $\mathrm{p}<0,0001$ \\
Female & $48,38 \pm 5,60$ & $32,38 \pm 3,69$ & $16,00 \pm 5,27$ & $32,57 \pm 8,11$ & $\mathrm{p}<0,0001$ \\
Male & $43,38 \pm 6,57$ & $30,38 \pm 5,53$ & $13,00 \pm 3,21$ & $30,04 \pm 6,90$ & $\mathrm{p}<0,0001$ \\
\hline
\end{tabular}

Table 4: Mean and standard deviation for HDL-cholesterol values ( $\mathrm{mg} / \mathrm{dL}$ ) according to age group.

\begin{tabular}{cccccc}
\hline Variable & $\begin{array}{c}\text { HDL-c }(\mathrm{mg} / \mathrm{dL}) \\
\text { Direct method }\end{array}$ & $\begin{array}{c}\text { HDL-c }(\mathrm{mg} / \mathrm{dL}) \\
\text { Method by precipitation }\end{array}$ & $\begin{array}{c}\text { Direct-precipitated HDL-c } \\
\text { variation }(\mathbf{m g} / \mathrm{dL})\end{array}$ & $\begin{array}{c}\text { \% change } \\
\text { Test t between HDL-c } \\
\text { direct-precipitate }\end{array}$ \\
\hline$\leq 18$ years & $60,20 \pm 7,22$ & $44,80 \pm 7,43$ & $15,40 \pm 0,89$ & $25,92 \pm 3,67$ & $\mathrm{p}<0,0001$ \\
19 a 60 years & $56,00 \pm 12,18$ & $40,16 \pm 8,30$ & $15,84 \pm 6,17$ & $27,83 \pm 7,25$ \\
> 60 years & $55,14 \pm 12,45$ & $37,10 \pm 8,61$ & $18,05 \pm 6,56$ & $\mathrm{p}<0,0001$ & \\
\hline
\end{tabular}

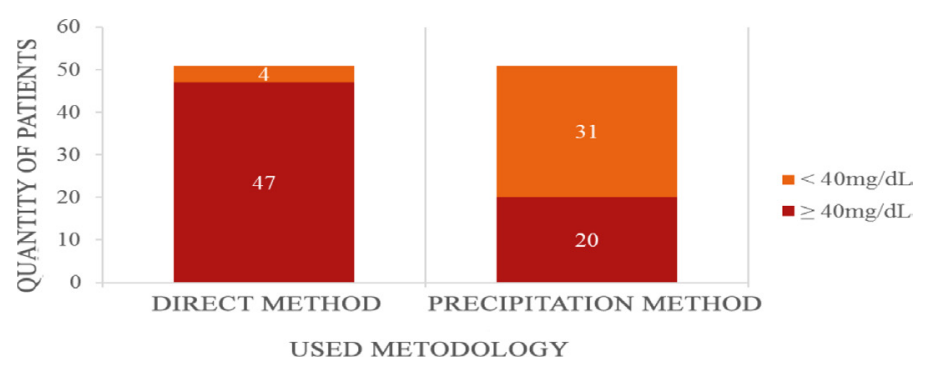

Figure 3: Quantitative of patients whose HDL-cholesterol values went from the desired reference levels with the change from direct to precipitation methodology.

HDL-cholesterol values between the direct method $(56.06 \pm 1.653)$ and the precipitation method $(39.35 \pm 1.193)$, as shown in Figure 1 .

Comparison of methods for HDL cholesterol dosage, direct vs. precipitation method $(y)$, resulted in the regression equation $y=0.6280 x+4.146$. The
Pearson correlation coefficient (r) between the methods was 0.8706, indicating a high correlation between the results (Figure 2).

From these data, the values of HDL-cholesterol were separated according to the reference values described in the literature: normal $(\geq 40 \mathrm{mg} / \mathrm{dL})$ and low $(<40 \mathrm{mg} / \mathrm{dL})$, considering for the separation of the groups the values obtained by precipitation method.

For normal HDL-cholesterol values ( $\geq 40 \mathrm{mg} / \mathrm{dL}$ ) according to the precipitation method, the results available in Table 2 were obtained.

For the low values of HDL-cholesterol $(<40 \mathrm{mg} / \mathrm{dL})$, considering the values obtained by the precipitation method, the results obtained are available in Table 3 .

It is also worth noting that $42.55 \%(\mathrm{n}=20)$ of HDL cholesterol values $\geq$ $40 \mathrm{mg} / \mathrm{dL}$ when analyzed by the direct method $(\mathrm{n}=47)$ showed HDLcholesterol levels $<40 \mathrm{mg} / \mathrm{dL}$ when analyzed by the method precipitation (Figure 3).

Finally, the results were divided into groups by age group, in order to verify a possible difference between the groups, as can be observed in Table 4. 


\section{DISCUSSION}

When analyzed the results found in each of the methodologies tested, an increase in the HDL-C values could be observed by the direct method when compared to the ones found by the precipitation method, being statistically significant this increase. When the groups were separated, patients with normal values of total cholesterol $(<200 \mathrm{mg} / \mathrm{dL})$ and altered (total cholesterol> $200 \mathrm{mg} / \mathrm{dL}$ ), the same result was observed.

In the present study, it was observed that there is a tendency of the HDLcholesterol values obtained by the direct method to provide higher results in relation to the precipitation method, considering that it is extremely important to alert the clinician to possible classification errors in borderline patients. ${ }^{4}$

The results of the evaluation between the two methodologies (direct and precipitated) for HDL-cholesterol obtained in this study were similar to the findings of another study in which the average HDL-cholesterol values between the direct and precipitation methods were also higher for the direct method, representing, on average, $29.54 \%$ above the precipitate. $^{15}$

Likewise, the results found in this study were also similar to those found by other authors, according to which the mean HDL-cholesterol values between the direct and precipitated methods were, on average, $27.75 \%$ higher for the direct method in relation to precipitate. ${ }^{4}$

Another related study analyzed the results found in each of the methodologies tested, an increase in the HDL-cholesterol values was observed by the direct method when compared to the ones found by the precipitation method, being statistically significant this increase. When patients with normal values of total cholesterol $(<200 \mathrm{mg} / \mathrm{dL})$ and patients with altered values (total cholesterol $>200 \mathrm{mg} / \mathrm{dL}$ ) were separated into groups, the same result was observed, evidencing that the difference between the values obtained is not related to the lipid level of the sample, which allows to affirm that the difference found is due to the methodology. ${ }^{3}$ The difference between the groups was found to be in groups with HDL cholesterol by direct method $\geq 40 \mathrm{mg} / \mathrm{dL}$ and $<40 \mathrm{mg} / \mathrm{dL}$, and it was observed that there was a significant difference $(p<0,0001)$ among the methodologies, reinforcing the theory that the results differ according to the technique used, and does not depend on the reference value at which the HDL-cholesterol values are found.

When evaluated by the direct method resulting in HDL-cholesterol levels > $40 \mathrm{mg} / \mathrm{dL}, 42.55 \%$ showed HDL-cholesterol levels < $40 \mathrm{mg} / \mathrm{dL}$ when analyzed by the precipitation method. Other studies obtained similar results: 31\% for Rocha and Cavalett, 2010 and 21\% for Caon and Tavares, 2013.

Despite the high correlation found between the methodologies (Pearson's $r=0.8706$ ), several significant differences were observed in the comparison of the direct and precipitation methods, it is important to emphasize the importance of knowledge and information of the method used for the clinical body, to that do not occur changes of conduct in function of the different results obtained with the different methodologies available in the market. The same was reported by another study, which obtained Pearson's $r$ even more expressive than the one found in the present study $(0,8933){ }^{3}$

Data were also separated by sex (female and male) and by age group $(<18$ years; between 19 and 60 years old; $>60$ years), for all groups analyzed a significant difference was observed, with $p<0.0001$. Again showing that the observed variations are independent of the variables of the samples, being correlated only to the differences between the methodologies used. However, when analyzed by age, a higher rate of change was observed with increasing age $(<18$ years $-25.92 \%, 19-60$ years $-27.83,>60$ years $-32.43 \%)$.
Considering that with increasing age there is a reduction in HDL cholesterol levels and an increase in the prevalence of cardiovascular diseases, it is possible that the variation in HDL-cholesterol levels is more significant in patients with lower HDL-cholesterol levels. The same is also observed when the groups with HDL-cholesterol levels below the reference value $(<40 \mathrm{mg} / \mathrm{dL})$ were analyzed, which showed a rate of change of $31.73 \%$, while those with HDL-cholesterol $\geq 40 \mathrm{mg} / \mathrm{dL}$ had a rate of change of $27.59 \%$.

One of the possible causes proposed for the generation of high HDL cholesterol results by the direct method may be an incomplete blocking of chylomicrons, VLDL and LDL by polyanion, which may be related to elevated triglyceride levels, allowing the enzymes to react with these fractions. Another reason to be considered is calibration, which can overestimate the HDL-cholesterol values for the homogeneous assays. ${ }^{15}$

\section{CONCLUSION}

It was possible to verify that there is a significant increase (of the order of $30 \%$ ) between the HDL-cholesterol values obtained by the direct method in relation to the method by independent precipitation of variables such as sex and age group; however, it was observed that increasing the rate of variation between the methods was more expressive; demonstrating the need to know the available methodologies and to pass this information on to the clinicians, since HDL-cholesterol and LDL-cholesterol dosages are routine in the clinical analysis laboratories and both analytes are extremely important in diagnosis and monitoring of dyslipidemias.

It is up to the laboratories to indicate the methodology used for HDL cholesterol dosage, so that the clinician having the knowledge of the available methodologies can monitor and / or correctly diagnose changes in serum lipids.

Further studies are needed in order to find a pattern of variation between the methods and allow the adequacy of the results through a correction factor or even of new reference values, so that both methodologies can be used correctly displaying the concentrations of HDL-cholesterol for each patient, guaranteeing an adequate behavior for each situation.

\section{ACKNOWLEDGEMENT}

Sincere thanks to the Laboratory of Clinical and Toxicological Analysis Prof. Dr. Eurico Litton Pinheiro de Freitas, place of research.

\section{CONFLICT OF INTEREST}

The authors declare no conflict of interest.

\section{REFERENCES}

1. Araki MV, Barros C, Santos EG. Análise do perfil lipídico de crianças e adolescentes do estado de Sergipe. Sci Plena. 2011;6(12).

2. Acevedo $\mathrm{M}$, et al. Relación colesterol total a HDL y colesterol no HDL: los mejores indicadores lipídicos de aumento de grosor de la íntima media carotidea. Rev méd Chile. 2012;140(8):969-76.

3. Caon LS, Tavares RG. Comparação de duas metodologias para determinação de colesterol HDL: Método direto versus método por precipitação. News Lab. 2013;119:100-6.

4. Rocha DE, Cavalett C. Análise comparativa entre duas metodologias para dosagem de HDL-C (direto e precipitado) em amostras heterogêneas. RBAC. 2010;42(3):227-30

5. Xavier HT, et al. Diretriz brasileira de dislipidemias e prevenção da aterosclerose. Arq Bras Cardiol. 2013;101(4):1-20

6. Lottenberg A. Importância da gordura alimentar na prevenção e no controle de distúrbios metabólicos e da doença cardiovascular. Arq Bras Endrinolgia Metabol. 2009;53(5):595-607.

7. Da Costa JF, Wagner R, DE Oliveira LC. Avaliação do risco cardiovascular em idosos residentes em asilos da grande Curitiba-PR. Cad da Esc Saúde. 2014;2(8).

8. De Oliveira LV, Sesti LF, De Oliveira S. Perfil lipídico e glicêmico em caminhoneiros da região central do estado do Rio Grande do Sul. Sci Plena. 2013;8(12).

9. Kreutz JC, et al. Diagnóstico Sobre a Incidência de Colesterol Elevado em 
Portela, et al:: Analysis of Two Methodologies for Determination of HDL Cholesterol

Moradores do Município de Serranópolis do Iguaçu, PR. Saúde e Pesqui. 2014;7(1).

10. Lima SC, Arrais RF, Almeida MG, Souza Z, Pedrosa LF. Perfil lipídico e peroxidação de lipídeos no plasma em crianças e adolescentes com sobrepeso e obesidade. J Pediatr (Rio J). 2004;80(1):23-8.

11. Souza N, visentainer J. Colesterol da mesa ao corpo. EDUEM. 2012;(2):117.

12. Chiesa $H$, Moresco RN, Bem A. Avaliação do risco cardíaco, conforme escores de risco de Framingham, em pacientes ambulatoriais de Salvador do Sul, São
Pedro da Serra e Barão - RS. Rev Saúde, St Maria. 2007;33(1):4-10.

13. Bioclin®. HDL direto K071. 2014.

14. Lucena M. Análise do perfil lipídico e glicídico de pacientes do município de Juazeirinho - PB. Universidade Estadual da Paraíba. 2014.

15. Leuckert A, Lucena DV, Casagrande L, Mattevi VS, Camargo JL. Nova alternativa para a dosagem de HDL-colesterol. RBAC. 1999;31(1):13-6.

Article History: Submission Date : 22-02-2018; Revised Date : 16-04-2018; Acceptance Date : 04-05-2018.

Cite this article: Portela RDP, Neto EMR, Júnior FJG, Ferreira JM, Alves RS. Comparative Analysis of Two Methodologies for Determination of HDL Cholesterol. J Young Pharm. 2018;10(3):308-12. 